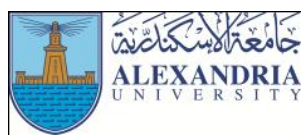

\title{
Electromyographic Comparison of Squash Backhand Shot after Midcourt and Frontcourt Traditional Movement Patterns
}

\author{
Tarek G. Alaaeldien ${ }^{1}$ \\ ${ }^{1}$ Faculty of Physical Education, Alexandria University, Alexandria, Egypt
}

\begin{abstract}
:
Electromyography of sixteen muscles of the lower limb, trunk, and upper limb muscles were compared between Backhand shot after traditional midcourt movement pattern and traditional frontcourt movement pattern of a three female squash players (age: $14.5 \pm 0.5$ years old; height $1.48 \pm 0.15 \mathrm{~m}$; mass: $44.67 \pm 1.53 \mathrm{Kg}$ ), ranked in the Squash National Egyptian team. Surface electromyographic (sEMG) electrodes were placed according to SENIAM guidelines on the skin, superficial to right-sided postural proximal of the trapezius, posterior deltoid, anterior deltoid, triceps brachii, biceps brachii, pectoralis major, serratus anterior, rectus abdominis, external abdominal, glutaeus medius, gluteus maximus, biceps femoris, rectus femoris, tibialis anterior, gastrocnemius, and soleus muscle. EMG data were 16 bit A/D converted at $1000 \mathrm{~Hz}$ and stored on computer. EMG signals were amplified (gain of 400), band pass filtered (10 to $500 \mathrm{~Hz})$, full wave rectified using root mean square average, and normalized to the isometric maximum voluntary contraction (MVC). Mean and standard deviation of the muscles activity (\%MVC) and work-loading (\% Total activity area) were calculated from the start of the two tasks to the end of Backhand shot recovery phase. The results showed that there were significant differences between both tasks in muscle activity of biceps brachii and gluteus maximus muscle, and the percentage of work-loading of rectus abdominis, gluteus maximus and biceps femoris.
\end{abstract}

Keywords: Muscle activity, Backhand, court movement patterns, squash.

\section{Introduction:}

$\mathrm{S}_{\mathrm{in}}^{\mathrm{a}}$ quash is a racket sport practiced by 15 million players in more than 135 countries (Meyer, Van Niekerk, Prinsloo, Steenkamp, \& Louw, 2009), where each point is won as a result of good court movement patterns and shots, which force the opponent off balance, and thus, the opponent executes inaccurate shots (Horobeanu \& Rosca, 2014). Further, in squash, the player starts with a split step on the $\mathrm{T}$ area, to be ready to move to the ball fast. Next, the player takes short steps or shuffles, to move to the direction of the ball and finishes with one or two large steps, to efficiently cover the court, and to be ready for the shot. Indeed, international players covers more distance during the whole game compared to national players $(500$ $\mathrm{m}$ Vs. $360 \mathrm{~m}$ ) due to the higher accuracy of international players strokes dictates longer moves from the $\mathrm{T}$ area to the stoke area and returning back to the T. (Goran Vuckovic, Dezman, Pers, \& Kovacic, 2005).

There are two main types of court movement patterns (traditional and dynamic). In particular, the traditional type occurs when the player hits the shot off the front foot, while the dynamic type occurs when the player hits the shot off the back foot. In addition, there are as well different shot types (forehand and backhand) which can be executed from different court areas (frontcourt, mid court, and backcourt) (Yarrow \& Harrison, 2010a).

It has been observed that backhand shot are more frequently used than forehand shot (Wilkinson, LeedaleBrown, \& Winter, 2009a). In addition, the backhand shot consists of three main phases (stance phase, swing phase, and follow throw phase). Likewise, on the backhand side, it is critical to turn the front shoulder toward the side wall. Indeed, the player lead with the front foot to make the shoulder turn more easily and tries to use traditional movement pattern on the backhand sides whenever possible(Yarrow \& Harrison, 2010a).

In order to identify strengths and weaknesses of the movement and shot characteristics of squash players, it is essential to have a data collection system that can reliably and accurately record these variables (Atkinson \& Nevill, 1998; G. Vuckovic et al., 2014). Further, test specificity is important to ensure validity and sensitivity of procedures and to help coaches and scientists in player assessment (Muller, Benko, Raschner, \& Schwameder, 2000; Wilkinson et al., 2012). 
Neuromuscular firing patterns and intramuscular coordination demands are factors that differentiate sport skill movements. Training therefore must likewise satisfy these demands that are specific to these movements (Gamble, 2010). Accordingly, electromyography (EMG) has been used to detect patterns of muscle activation but there have been very few applications in racket sports. Recently, Alaaeldien and Akll (2016) reported EMG data on forehand shot after two different traditional court movement patterns, while Sakurai and Ohtsuki (2000) reported EMG data on the muscles that control wrist actions (the extensor carpi radialis and flexor carpi radialis) in the $50 \mathrm{~ms}$ before impact..

To the researcher knowledge, no published studies have quantified the muscle activity of the lower limb, trunk, and upper limb muscles that contribution in backhand shot performance after court movement patterns. Therefore, the present study compares the changes occurring in squash backhand shot muscle activity after midcourt and frontcourt traditional movement patterns.

Figure (1)

Traditional midcourt movement pattern

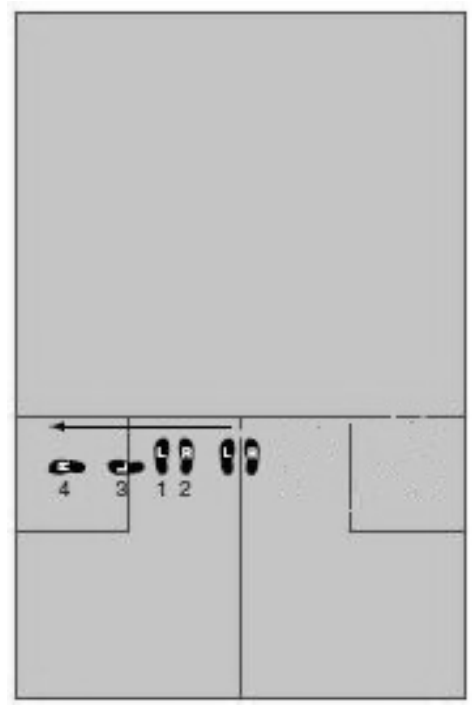

Surface electromyography

Self-adhesive, silver-silver chloride surface electromyographic (sEMG) electrodes (SKINTACT, FS521), Innsbruck, Austria) were placed according to SENIAM guidelines on the skin, superficial to right-sided postural proximal of the following sixteen muscles: Trapezius muscle (T), Posterior Deltoid muscle (D-p), Anterior Deltoid muscle (D-a), Triceps brachii muscle (TB), Biceps brachii muscle (BB), Pectoralis major muscle (PM), serratus anterior muscle (S-a), Rectus abdominis muscle (RA), External abdominal muscle (EA),

\section{Material and methods:}

Three female squash players (age: $14.5 \pm 0.5$ years old; height $1.48 \pm 0.15 \mathrm{~m}$; mass: $44.67 \pm 1.53 \mathrm{Kg}$ ), ranked in the National Egyptian team, participated in this study. The parental consent of all players was obtained. This study was approved by the institutional ethics committee of studies and researches. The Participants was asked to execute two tasks (Yarrow \& Harrison, 2010b). The first task (task 1) was to shadow a squash backhand shot after traditional midcourt movement pattern, starting from the $\mathrm{T}$ with a split step and moving to the left with a sidestepping motion, executing backhand shadow shot and return back to the $\mathrm{T}$ (Figure. 1). The second task (task 2) was to shadow a backhand shot after traditional frontcourt movement pattern, starting from the $\mathrm{T}$ area with a split step and moving forward in $\mathrm{J}$ shape toward the left forecourt, executing a backhand shadow shot and retreats to the $\mathrm{T}$ area (Figure. 2), (Yarrow \& Harrison, 2010b).

Figure (2)

Traditional frontcourt movement pattern

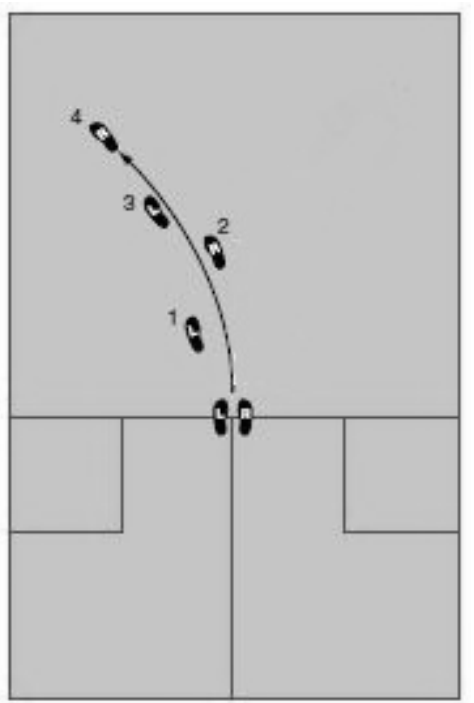

Glutaeus medius muscle (G-med), Gluteus maximus muscle (G-max), Biceps femoris muscle (BF), Rectus Femoris muscle (RF), Tibialis anterior muscle (T-a), Gastrocnemius muscle (Gas), and Soleus muscle (Sol) (Hermens, Freriks, Disselhorst-Klug, \& Rau). The skin overlying the largest visible section of the muscle was prepared by having the subject shave any overlying hair and clean the area vigorously with isopropyl alcohol, to reduce electromyography (EMG) signal impedance. A wireless EMG system (MEGAWIN version 3.1-b12 software, Finland) with a sampling rate of $1000 \mathrm{HZ}$ per channel was used to measure muscle activity of the sixteen 
muscles in three conditions. EMG data were band -pass filtered at 10-500 $\mathrm{HZ}$ and full wave rectified using Average root mean square (Electronics, 2008). The first measurement for each of the sixteen muscles was to have the subjects to perform three trials of isometric maximum voluntary contraction (MVC). Each MVC was performed for $5 \mathrm{~s}$, with 30-60 s rest in between. The highest value of MVC in the three trials for each muscle was used. The second and third measurements were to measure the EMG activity during two different tasks (task 1 and task 2). A fifteen minute warm-up which included general and shoulder-specific mobility exercises, as well as stretch exercises and familiarization trials, were required before players' trials. A total of three trials were recorded for each participant, with one minute rest between trials, the best trial for each participant was selected for analysis. A quantitative analysis of EMG activity was reported by normalizing EMG out. The technique involved the transformation of the EMG signals during the two tasks to a percentage of the signal recorded for maximum voluntary contraction (\%MVC) of each muscle being investigated. This normalizing technique was used to compare the changes occurring in Backhand shot muscle activity with changes in activity conditions (after traditional midcourt movement pattern vs. after traditional frontcourt movement pattern). In order to get the temporal, and muscles work loading, plunger events were used to mark the starting time, and the end of forehand shot recovery phase for both tasks. The ME6000 system equipped with user friendly MegaWin PC-software (Mega Electronics Ltd.) was used for data transfer, analysis, and storage (Electronics, 2008).

\section{Statistical analysis}

For the statistical analysis of the data, the IBM SPSS Statistics 21 was used. Descriptive statistics, KolmogorovSmirnov and Shapiro-Wilk tests were used to check for data normality; results show that the activity and workloading of the selected muscles have a normal distribution. After that, the T-test for independent samples was used to compare the changes occurring in squash Backhand shot muscle activity after traditional midcourt movement pattern vs. traditional frontcourt movement pattern.

\section{Results:}

Table (1)

Descriptive Values and T-test of RMS Muscle Activity (\%MVC) during Backhand Shot after Traditional Midcourt Movement Pattern and Traditional Frontcourt Movement Pattern

\begin{tabular}{|c|c|c|c|c|c|c|}
\hline \multirow{2}{*}{$\begin{array}{l}\text { Skills / Muscles } \\
\text { (\% MVC) }\end{array}$} & \multicolumn{2}{|c|}{$\begin{array}{c}\text { Backhand shot after traditional midcourt } \\
\text { movement pattern }\end{array}$} & \multicolumn{2}{|c|}{$\begin{array}{c}\text { Backhand shot after traditional frontcourt } \\
\text { movement pattern }\end{array}$} & \multirow[t]{2}{*}{$\mathbf{T}$} & \multirow{2}{*}{ Sig. } \\
\hline & M & $\mathrm{SD}$ & M & $\mathrm{SD}$ & & \\
\hline Trapezius & 3.93 & 0.43 & 3.89 & 0.80 & .057 & 0.96 \\
\hline Posterior Deltoid & 16.93 & 3.17 & 16.16 & 1.61 & .373 & 0.73 \\
\hline Anterior Deltoid & 6.44 & 0.99 & 6.87 & 1.17 & -.481 & 0.66 \\
\hline Triceps brachii & 3.87 & 0.43 & 4.06 & 0.63 & -.431 & 0.69 \\
\hline Biceps brachii & 9.04 & 0.47 & 10.86 & 1.02 & -2.822 & 0.05 \\
\hline Pectoralis major & 7.58 & 1.27 & 8.31 & 0.96 & -.799 & 0.47 \\
\hline serratus anterior & 3.64 & 0.82 & 5.19 & 1.58 & -1.516 & 0.20 \\
\hline Rectus abdominis & 3.78 & 0.72 & 5.70 & 1.13 & -2.488 & 0.07 \\
\hline External abdominal & 9.51 & 1.34 & 11.96 & 2.67 & -1.422 & 0.23 \\
\hline Glutaeus medius & 23.06 & 3.65 & 24.24 & 2.81 & -.4 & 0.68 \\
\hline Gluteus maximus & 12.08 & 0.65 & 15.10 & 1.54 & -3.126 & 0.04 \\
\hline Biceps femoris & 22.98 & 4.81 & 29.57 & 3.10 & -1.995 & 0.12 \\
\hline Rectus femoris & 10.76 & 0.92 & 11.82 & 0.93 & -1.406 & 0.23 \\
\hline Tibialis anterior & 16.16 & 2.50 & 17.14 & 0.50 & -.668 & 0.54 \\
\hline Gastrocnemius & 11.88 & 4.47 & 13.77 & 3.04 & -.606 & 0.58 \\
\hline Soleus & 23.09 & 4.47 & 23.32 & 2.13 & -.080 & 0.94 \\
\hline
\end{tabular}


Figure (3)

RMS muscle activity (\%MVC) Backhand shot after traditional midcourt movement pattern and traditional frontcourt movement pattern. $\mathrm{T}=$ Trapezius muscle, $\mathrm{D}-\mathrm{p}=$ Posterior Deltoid muscle, $\mathrm{D}-\mathrm{a}=$ Anterior Deltoid muscle, $\mathrm{TB}=$ Triceps brachii muscle, $\mathrm{BB}=\mathrm{Biceps}$ brachii muscle, $\mathrm{PM}=$ Pectoralis major muscle, $\mathrm{S}-\mathrm{a}=$ serratus anterior muscle, $\mathrm{RA}=$ Rectus abdominis muscle, $\mathrm{EA}=$ External abdominal muscle,

G-med =Glutaeus medius muscle, $\mathrm{G}-\mathrm{max}=$ Gluteus maximus muscle, $\mathrm{BF}=\mathrm{Biceps}$ femoris muscle, $\mathrm{RF}=\mathrm{Rectus}$ femoris muscle, $\mathrm{T}$-a

$=$ Tibialis anterior muscle, Gas $=$ Gastrocnemius muscle, Sol=Soleus muscle .

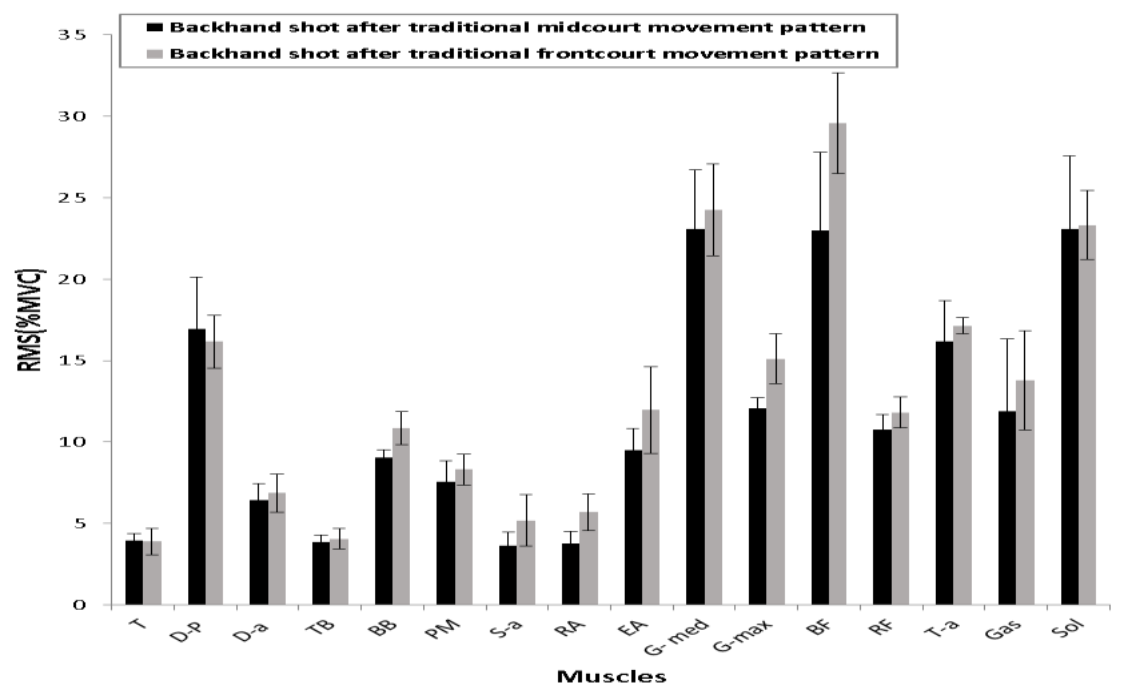

Table (2)

Descriptive Values and T-test of Muscles Work-loading (\% Total area) during Backhand Shot after

Traditional Midcourt Movement Pattern vs. Traditional Frontcourt Movement Pattern.

\begin{tabular}{|c|c|c|c|c|c|c|}
\hline \multirow{2}{*}{$\begin{array}{l}\text { Skills / Muscles } \\
\text { (\% total area) }\end{array}$} & \multicolumn{2}{|c|}{$\begin{array}{c}\text { Backhand shot after traditional midcourt } \\
\text { movement pattern }\end{array}$} & \multicolumn{2}{|c|}{$\begin{array}{c}\text { Backhand shot after traditional frontcourt } \\
\text { movement pattern }\end{array}$} & \multirow[t]{2}{*}{$\mathbf{T}$} & \multirow[t]{2}{*}{ Sig. } \\
\hline & M & SD & M & SD & & \\
\hline Trapezius & 10.23 & 0.92 & 9.18 & 1.55 & 1.01 & 0.37 \\
\hline Posterior Deltoid & 12.58 & 1.13 & 10.98 & 0.22 & 2.41 & 0.07 \\
\hline Anterior Deltoid & 5.43 & 0.24 & 5.25 & 0.25 & 0.88 & 0.43 \\
\hline Triceps brachii & 3.11 & 0.37 & 2.95 & 0.19 & 0.69 & 0.53 \\
\hline Biceps brachii & 4.06 & 0.38 & 4.41 & 0.23 & -1.39 & 0.24 \\
\hline Pectoralis major & 2.49 & 0.12 & 2.49 & 0.14 & -0.03 & 0.98 \\
\hline serratus anterior & 2.66 & 0.33 & 3.42 & 0.62 & -1.89 & 0.13 \\
\hline Rectus abdominis & 1.71 & 0.13 & 2.34 & 0.21 & -4.51 & 0.01 \\
\hline $\begin{array}{c}\text { External } \\
\text { abdominal }\end{array}$ & 2.79 & 0.06 & 3.17 & 0.32 & -2.03 & 0.11 \\
\hline Glutaeus medius & 4.11 & 0.15 & 3.94 & 0.18 & 1.23 & 0.29 \\
\hline Gluteus maximus & 3.51 & 0.22 & 3.97 & 0.08 & -3.37 & 0.03 \\
\hline Biceps femoris & 7.29 & 0.64 & 8.59 & 0.27 & -3.26 & 0.03 \\
\hline Rectus Femoris & 7.94 & 0.60 & 7.92 & 0.32 & 0.05 & 0.96 \\
\hline Tibialis anterior & 13.62 & 3.39 & 12.96 & 1.12 & 0.32 & 0.77 \\
\hline Gastrocnemius & 9.44 & 2.34 & 10.07 & 1.20 & -0.42 & 0.70 \\
\hline Soleus & 9.04 & 0.95 & 8.36 & 0.33 & 1.19 & 0.30 \\
\hline
\end{tabular}


Figure (4)

Muscles work-loading (\% Total area) during Backhand shot after traditional midcourt movement pattern and traditional frontcourt movement pattern. T=Trapezius muscle, D-p =Posterior Deltoid muscle, D-a=Anterior Deltoid muscle, TB=Triceps brachii muscle, BB $=$ Biceps brachii muscle, $\mathrm{PM}=$ Pectoralis major muscle, $\mathrm{S}-\mathrm{a}=$ serratus anterior muscle, $\mathrm{RA}=$ Rectus abdominis muscle, $\mathrm{EA}=\mathrm{External}$ abdominal muscle, G-med=Glutaeus medius muscle, G-max=Gluteus maximus muscle, BF=Biceps femoris muscle, RF=Rectus femoris muscle, $\mathrm{T}-\mathrm{a}=$ Tibialis anterior muscle, $\mathrm{Gas}=\mathrm{Gastrocnemius} \mathrm{muscle}$, Sol=Soleus muscle.

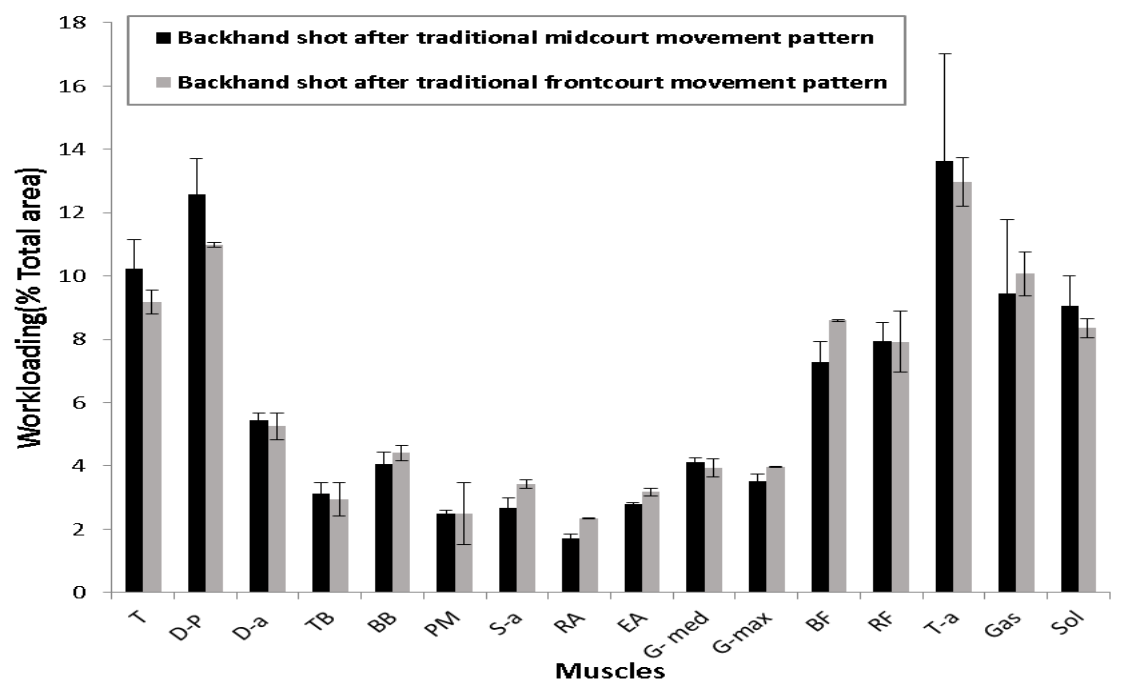

\section{Discussion:}

Modern Squash game requires frequent stroke hit associated with different court movement patterns. Besides, good court movements will enable the player to position himself better for shots and be able to cover the opponents' shots more quickly and efficiently. Also, the literature classifies these court patterns as either traditional or dynamic. Indeed, knowledge of muscles activity profile responsible for these movement patterns will fill a gap in the scientific literature.

Muscles such as the Trapezius muscle (T), Posterior Deltoid muscle (D-p), Anterior Deltoid muscle (D-a), Triceps Brachii muscle (TB), Biceps Brachii muscle (BB), Pectoralis Major muscle (PM), Serratus Anterior muscle (S-a), Rectus Abdominis muscle (RA), External Abdominal muscle (EA), Glutaeus Medius muscle (Gmed), Gluteus Maximus muscle (G-max), Biceps Femoris muscle (BF), Rectus Femoris muscle (RF), Tibialis Anterior muscle (T-a), Gastrocnemius muscle (Gas), and Soleus muscle (Sol) burst in a coordinated pattern, to execute effective shots, and secure working joints from injuries.(Alaaeldien \& Akll, 2016)

So, the present study focused on determining the muscle activity and comparing the changes occurring in squash backhand shot muscle activity after traditional midcourt movement pattern (pattern 1) versus traditional frontcourt movement pattern (pattern 2). To the researcher knowledge, this is the first study to investigate both backhand movement patterns in squash.

Firstly, the main findings of the current study were the ranking between both \%MVC backhand patterns in ordinal terms as well as understanding how much effort a certain muscle had to share in both patterns (Table 1, Figure 3). RMS muscle activity (\%MVC), during backhand shot after traditional midcourt movement pattern, ranked in descending order, were as follows: $\operatorname{Sol}(\mathrm{M}=23.09, \quad \mathrm{SD}=4.47) \quad \mathrm{G}-\operatorname{med}(\mathrm{M}=23.06, \quad \mathrm{SD}=3.65)$, $\mathrm{BF}(\mathrm{M}=22.98, \quad \mathrm{SD}=4.81), \mathrm{D}-\mathrm{p}(\mathrm{M}=16.93, \mathrm{SD}=3.17), \mathrm{T}-$ $\mathrm{a}(\mathrm{M}=16.16, \quad \mathrm{SD}=2.5), \quad \mathrm{G}-\max (\mathrm{M}=12.08, \quad \mathrm{SD}=0.65)$, $\operatorname{Gas}(\mathrm{M}=11.88, \quad \mathrm{SD}=4.47), \quad \mathrm{RF}(\mathrm{M}=10.76, \quad \mathrm{SD}=0.92)$, $\mathrm{EA}(\mathrm{M}=9.51, \quad \mathrm{SD}=1.34), \quad \mathrm{BB}(\mathrm{M}=9.04, \quad \mathrm{SD}=0.47)$, $\mathrm{PM}(\mathrm{M}=7.58, \quad \mathrm{SD}=1.27), \quad \mathrm{D}-\mathrm{a}(\mathrm{M}=6.44, \quad \mathrm{SD}=0.99)$, $\mathrm{T}(\mathrm{M}=3.93, \quad \mathrm{SD}=0.43), \quad \mathrm{TB}(\mathrm{M}=3.87, \quad \mathrm{SD}=0.43)$, $\mathrm{RA}(\mathrm{M}=3.78, \mathrm{SD}=0.72), \mathrm{S}-\mathrm{a}(\mathrm{M}=3.64, \mathrm{SD}=0.82)$. whereas, RMS muscle activity (\%MVC), during backhand shot after traditional frontcourt movement pattern, ranked in descending order, were as follows: $\mathrm{BF}(\mathrm{M}=29.57, \mathrm{SD}=3.1)$, G-med(M=24.24, SD=2.81), $\operatorname{Sol}(M=23.32, S D=2.13)$, $T$ $\mathrm{a}(\mathrm{M}=17.14, \quad \mathrm{SD}=0.5), \quad \mathrm{D}-\mathrm{p}(\mathrm{M}=16.16, \quad \mathrm{SD}=1.61), \quad \mathrm{G}-$ $\max (\mathrm{M}=15.1, \quad \mathrm{SD}=1.54), \quad \mathrm{Gas}(\mathrm{M}=13.77, \quad \mathrm{SD}=3.04)$, $\mathrm{EA}(\mathrm{M}=11.96, \quad \mathrm{SD}=2.67), \quad \mathrm{RF}(\mathrm{M}=11.82, \quad \mathrm{SD}=0.93)$, $\mathrm{BB}(\mathrm{M}=10.86, \quad \mathrm{SD}=1.02), \quad \mathrm{PM}(\mathrm{M}=8.31, \quad \mathrm{SD}=0.96), \quad \mathrm{D}-$ $\mathrm{a}(\mathrm{M}=6.87, \mathrm{SD}=1.17), \mathrm{RA}(\mathrm{M}=5.7, \mathrm{SD}=1.13), \mathrm{S}-\mathrm{a}(\mathrm{M}=5.19$, $\mathrm{SD}=1.58), \mathrm{TB}(\mathrm{M}=4.06, \mathrm{SD}=0.63), \mathrm{T}(\mathrm{M}=3.89, \mathrm{SD}=0.8)$. 
These results are in good agreement with other studies which have shown that the lower limb muscles were the most active during the performance (Table 1, Figure 3), because both backhand patterns start with a split step, during which the gluteus maximus, glutaeus medius, biceps femoris, and rectus femoris, the gastrocnemius, tibialis anterior, and soleus muscles absorb the shock of touching down on the ground, and typically they fire explosively in the push off from the $\mathrm{T}$ and provide a solid base when hitting a shot from an open stance. Afterward, lower limb muscles need to rapidly break the horizontal and vertical momentum during the lunge to return back to the T area. (Alaaeldien \& Akll, 2016; Elliott, 2006; Roetert \& Kovacs, 2011).

This kind of evaluation is important to understand the effect of both patterns on \% MVC and reveal their character of being low, submaximal or maximal in demand. Subsequently, by understanding the neuromuscular demands of backhand patterns, coaches may use these results in: designing efficient strength training exercises suitable for such patterns, and improving technique.(Konrad, 2006)

Secondly, muscles work-loading (\% Total area) (Table 2, Figure 4), during backhand shot after traditional midcourt movement pattern, ranked in descending order, were as follows: $\quad \mathrm{T}-\mathrm{a}(\mathrm{M}=13.62, \quad \mathrm{SD}=3.39), \quad \mathrm{D}-\mathrm{p}(\mathrm{M}=12.58$, $\mathrm{SD}=1.13), \quad \mathrm{T}(\mathrm{M}=10.23, \quad \mathrm{SD}=0.92), \quad \mathrm{Gas}(\mathrm{M}=9.44$, $\mathrm{SD}=2.34)$, Sol(M=9.04, $\mathrm{SD}=0.95), \mathrm{RF}(\mathrm{M}=7.94, \mathrm{SD}=0.6)$, $\mathrm{BF}(\mathrm{M}=7.29, \quad \mathrm{SD}=0.64), \quad \mathrm{D}-\mathrm{a}(\mathrm{M}=5.43, \quad \mathrm{SD}=0.24), \quad \mathrm{G}-$ $\operatorname{med}(\mathrm{M}=4.11, \quad \mathrm{SD}=0.15), \quad \mathrm{BB}(\mathrm{M}=4.06, \quad \mathrm{SD}=0.38), \quad \mathrm{G}-$ $\max (\mathrm{M}=3.51, \quad \mathrm{SD}=0.22), \quad \mathrm{TB}(\mathrm{M}=3.11, \quad \mathrm{SD}=0.37)$, $\mathrm{EA}(\mathrm{M}=2.79, \quad \mathrm{SD}=0.06), \quad \mathrm{S}-\mathrm{a}(\mathrm{M}=2.66, \quad \mathrm{SD}=0.33)$, $\mathrm{PM}(\mathrm{M}=2.49, \mathrm{SD}=0.12), \mathrm{RA}(\mathrm{M}=1.71, \mathrm{SD}=0.13)$. Whereas, muscles work-loading (\% Total area) (Table 2, Figure 4), during backhand shot after traditional frontcourt movement pattern, ranked in descending order, were as follows: $\quad \mathrm{T}-\mathrm{a}(\mathrm{M}=12.96, \quad \mathrm{SD}=1.12), \quad \mathrm{D}-\mathrm{p}(\mathrm{M}=10.98$, $\mathrm{SD}=0.22)$, Gas $(\mathrm{M}=10.07, \mathrm{SD}=1.2), \mathrm{T}(\mathrm{M}=9.18, \mathrm{SD}=1.55)$, $\mathrm{BF}(\mathrm{M}=8.59, \quad \mathrm{SD}=0.27), \quad \mathrm{Sol}(\mathrm{M}=8.36, \quad \mathrm{SD}=0.33)$, $\mathrm{RF}(\mathrm{M}=7.92, \quad \mathrm{SD}=0.32), \quad \mathrm{D}-\mathrm{a}(\mathrm{M}=5.25, \quad \mathrm{SD}=0.25)$, $\mathrm{BB}(\mathrm{M}=4.41, \mathrm{SD}=0.23), \mathrm{G}-\max (\mathrm{M}=3.97, \mathrm{SD}=0.08), \mathrm{G}-$ $\operatorname{med}(\mathrm{M}=3.94, \quad \mathrm{SD}=0.18), \quad \mathrm{S}-\mathrm{a}(\mathrm{M}=3.42, \quad \mathrm{SD}=0.62)$, $\mathrm{EA}(\mathrm{M}=3.17, \quad \mathrm{SD}=0.32), \quad \mathrm{TB}(\mathrm{M}=2.95, \quad \mathrm{SD}=0.19)$, $\operatorname{PM}(M=2.49, \quad S D=0.14), \quad R A(M=2.34, \quad S D=0.21)$. The ranked Muscle work-loading results in both backhand patterns quantify the relative contribution of the muscle synergy to the overall muscle activity pattern (TorresOviedo and Ting, 2007; Hug et al., 2010). Consequently, these results provide a simplified neural control strategy for the control of these complex movements patterns (Raasch and Zajac, 1999, Hug, 2011).
Thirdly, the present study showed that the muscle activity profile difference between both backhand patterns are in biceps brachii (P-value<0.05), and gluteus maximus muscle ( $\mathrm{P}$-value $<0.04)$, and no differences existed in the other selected muscles (Table 1, Figure 3).. Also, there were differences in percentage of work-loading of rectus abdominis (P-value<0.01), gluteus maximus ( $\mathrm{P}$ value $<0.03$ ), and biceps femoris $(\mathrm{P}$-value<0.03) (Table 2 , Figure 4).

More important, Biceps brachii fires more during the 2nd backhand pattern since it is responsible for flexing the elbow close to the body during the backhand backswing phase; and responsible for adjusting the speed of elbow extension during the backhand forward swing and follow through phases. Subsequently, Biceps brachii contracts concentrically as an agonist muscle in the backhand backswing phase and then, it contracts eccentrically in backhand forward swing and follow-through phases.(Roetert \& Kovacs, 2011)

Similarly, Gluteus maximus and biceps femoris fire more in 2nd backhand pattern, since they are responsible for hip extension movements and are required for lower body deceleration, stopping and changing direction. The stronger the hamstring and hip extension strength, the more force a player can handle. This allows squash player to stop faster and change direction quicker. Hamstring and gluteal eccentric strength are needed when landing on open-stance groundstrokes and especially when hitting low volleys that require great stability at contact. Closedstance backhand volleys are a great example of when the hamstrings and gluteals are activated eccentrically to successfully execute the stroke. (Alaaeldien \& Akll, 2016; Roetert \& Kovacs, 2011).

In addition, compared to the 1 st backhand pattern, RA muscle fires more during the last step of the 2nd backhand pattern. This finding reflects the higher muscle demands in the 2nd backhand pattern to flex the core forward, to reach the shadow ball in the front court corner, and to control the rotational movement of the core. Lastly, there are no differences existed in the other muscles, because they are working in the same pattern manner in the two backhand shots.

In brief, current research results suggest that backhand pattern really does have an effect in RMS muscle activity (\%MVC), and muscle work loading (\% Total area). Specifically, second backhand pattern records higher $\% \mathrm{MVC}$ of biceps brachii muscle and gluteus maximus muscle, and higher \% Total area of rectus abdominis, gluteus maximus, and biceps femoris. In particular, when backhand pattern changes from pattern1 to pattern 2, during the last step of the 2 nd pattern, the players widen 
their crossover step (last step) to reach the shadow ball in the front court corner, resulting in a higher RA muscle activity to flex the core forward and to fixate core spiral rotation. Consequently, to regulate this down movement during the last step lunge, the gluteus maximus, and biceps femoris fire more eccentrically and then concentrically to extent the core and execute the backhand forward swing and follow throw phases. Of equal importance, during backswing phase in the 2nd backhand pattern, biceps brachii muscle fires more concentrically to flex the glenohumeral and elbow joints. Then, it contracts eccentrically in the follow throw phase, to decelerate the arm motion. Also, biceps plays an important role in supporting the other muscles around the shoulder and upper back. The ranked muscle work-loading results in both backhand patterns quantify the relative contribution of the muscle synergy to the overall muscle activity pattern (François Hug, Turpin, Guével, \& Dorel, 2010; Ting \& McKay, 2007; Torres-Oviedo \& Ting, 2007). Indeed, these results provide a simplified neural control strategy for the control of these complex movement patterns (F. Hug, 2011; Raasch \& Zajac, 1999).

\section{Conclusion:}

The present study focused on determining the muscle activity and comparing the changes occurring in squash Backhand shot muscle activity after traditional midcourt movement pattern (pattern 1) versus traditional frontcourt movement pattern (pattern 2). The study determined the muscle activity (\% MVC) for the sixteen selected muscles during the two patterns of Backhand shots, and the percentage of work-loading (\% Total activity area) for each muscle. This paper has clearly shown that the muscle activity profile difference between both Backhand patterns are in biceps brachii ( $\mathrm{P}$-value $<0.05)$, and gluteus maximus muscle ( $\mathrm{P}$-value $<0.04$ ), and no differences existed in the other selected muscles. Also, there were differences in percentage of work-loading of rectus abdominis (Pvalue $<0.01)$, gluteus maximus $(\mathrm{P}$-value $<0.03)$, and biceps femoris $(\mathrm{P}$-value $<0.03)$. These results may help coaches and players for understanding more about muscle activity during the two patterns of Backhand shots, and improving the players' performance. On the basis of the promising findings presented in this paper, work on other skills and movement patterns is continuing and will be presented in future papers.

\section{References:}

1- Alaaeldien, T. G., \& Akll, A. R. I. (2016). Electromyographic comparison of squash forehand shot after midcourt and frontcourt traditional movement patterns. Sports Sci. Pract. Asp. Sport Scientific and Practical Aspects, 13(1), 19-25.

2- Atkinson, G., \& Nevill, A. M. (1998). Statistical methods for assessing measurement error (reliability) in variables relevant to sports medicine. Sports Med, 26(4), 217-238.

3- Electronics, M. (2008). MegaWin 3.0 Software User Manual (pp. 1-197). KUOPIO, FINLAND: Mega Electronics Ltd.

4- Elliott, B. (2006). Biomechanics and tennis. Br J Sports Med, 40(5), 392-396. doi: 10.1136/bjsm.2005.023150

5- Gamble, P. (2010). Strength and conditioning for team sports : sport-specific physical preparation for high performance. Milton Park, Abingdon, Oxon; New York, NY: Routledge.

6- Hermens, H. J., Freriks, B., Disselhorst-Klug, C., \& Rau, G. Development of recommendations for SEMG sensors and sensor placement procedures. Journal of Electromyography and Kinesiology, 10(5), 361-374. doi: 10.1016/S1050-6411(00)00027-4

7- Horobeanu, C., \& Rosca, A. (2014). SQUASH - AN (POSSIBLE) OLYMPIC SPORT. Discobolul - Physical Education, Sport and Kinetotherapy Journal, Vol. X no.1(35), 24-29.

8- Hug, F. (2011). Can muscle coordination be precisely studied by surface electromyography? J Electromyogr Kinesiol, 21(1), 1-12. doi: 10.1016/j.jelekin.2010.08.009

9- Hug, F., Turpin, N. A., Guével, A., \& Dorel, S. (2010). Is interindividual variability of EMG patterns in trained cyclists related to different muscle synergies? . J Appl Physiol, 108(6), 1727-1736. doi: 10.1152/japplphysiol.01305.2009.-Our

10- Konrad, P. (2006). The ABC of EMG-A Practical Introduction to Kinesiological Electromyography. USA: Noraxon INC.

11- Lin, C. F., Hua, S. H., Huang, M. T., Lee, H. H., \& Liao, J. C. (2015). Biomechanical analysis of knee and trunk in badminton players with and without knee pain during backhand diagonal lunges. J Sports Sci, 33(14), 1429-1439. doi: 10.1080/02640414.2014.990492

12- Meyer, L., Van Niekerk, L., Prinsloo, E., Steenkamp, M., \& Louw, Q. (2009). Prevalence of musculoskeletal injuries among adolescent squash players in the Western Cape. S Afr J SM South African Journal of Sports Medicine, 19(1), 3. 
13- Micklewright, D., \& Papapdopoulou, E. (2008). A new squash specific incremental field test. Int $\mathbf{J}$ Sports Med, 29(9), 758-763. doi: 10.1055/s-2008-1038431

14- Muller, E., Benko, U., Raschner, C., \& Schwameder, H. (2000). Specific fitness training and testing in competitive sports. Med Sci Sports Exerc, 32(1), 216-220.

15- Raasch, C. C., \& Zajac, F. E. (1999). Locomotor Strategy for Pedaling: Muscle Groups and Biomechanical Functions. Journal of Neurophysiology, 82(2), 515-525.

16- Reid, M., Elliott, B., \& Crespo, M. (2013 ). Mechanics and Learning Practices Associated with the Tennis Forehand: A Review. Journal of Sports Science and Medicine, 12, 225-231.

17- Roddy, R., Lamb, K., \& Worsfold, P. (2014). The importance of perturbations in elite squash: An analysis of their ability to successfully predict rally outcome. International Journal of Performance Analysis in Sport, 14, 652-679.

18- Roetert, P., \& Kovacs, M. (2011). Tennis anatomy. Champaign, IL: Human Kinetics.

19- Sakurai, S., \& Ohtsuki, T. (2000). Muscle activity and accuracy of performance of the smash stroke in badminton with reference to skill and practice. J Sports Sci, 18(11), 901-914. doi: 10.1080/026404100750017832

20- Ting, L. H., \& McKay, J. L. (2007). Neuromechanics of muscle synergies for posture and movement. Curr Opin Neurobiol, 17(6), 622-628. doi: 10.1016/j.conb.2008.01.002
21- Torres-Oviedo, G., \& Ting, L. H. (2007). Muscle Synergies Characterizing Human Postural Responses. Journal of Neurophysiology, 98(4), 2144-2156. doi: 10.1152/jn.01360.2006

22- Vuckovic, G., Dezman, B., Pers, J., \& Kovacic, S. (2005). Motion analysis of the international and national rank squash players. ISPA 2005, 334-338.

23- Vuckovic, G., James, N., Hughes, M., Murray, S., Milanovic, Z., Pers, J., \& Sporis, G. (2014). A new method for assessing squash tactics using 15 court areas for ball locations. Hum Mov Sci, 34, 81-90. doi: 10.1016/j.humov.2014.01.002

24- Wilkinson, M., Cooke, M., Murray, S., Thompson, K. G., St Clair Gibson, A., \& Winter, E. M. (2012). Physiological correlates of multiple-sprint ability and performance in international-standard squash players. $\mathbf{J}$ Strength Cond Res, 26(2), 540-547. doi: 10.1519/JSC.0b013e318220ddbb

25- Wilkinson, M., Leedale-Brown, D., \& Winter, E. M. (2009a). Validity of a squash-specific fitness test. International journal of sports physiology and performance, 4(1), 29-40.

26- Wilkinson, M., Leedale-Brown, D., \& Winter, E. M. (2009b). Validity of a squash-specific fitness test. Int J Sports Physiol Perform, 4(1), 29-40.

27- Yarrow, P., \& Harrison, A. (2010a). Squash : steps to success. Champaign, IL: Human Kinetics.

28- Yarrow, P., \& Harrison, A. (2010b). Squash : steps to success. United States of America: Human Kinetics. 